\title{
ESTUDO DA MATURAÇÃO DE SEMENTES DE CARVALHO VERMELHO (Miconia cinnamomifolia (Dc.) Naud.)
}

\author{
Maturity of Miconia cinnamomifolia (DC.) Naud seed red oak
}

\author{
José Carlos Lopes ${ }^{1}$, Aline da Silva Soares ${ }^{2}$
}

\begin{abstract}
RESUMO
Miconia cinnamomifolia é uma planta arbórea da família Melastomataceae, indicada para arborização de parques, jardins e reflorestamentos, devido à procura de seus frutos pela avifauna, e cuja madeira é empregada na construção civil, mourões, postes, dormentes e em obras submersas. Objetivou-se com este trabalho estudar a maturação fisiológica de sementes de Miconia cinnamomifolia. Os estudos foram conduzidos na Serra do Caparaó, município de Ibitirama-ES, onde periodicamente foram etiquetadas flores e acompanhado o enchimento dos frutos e desenvolvimento das sementes até que atingissem a completa maturação e, no Laboratório de Tecnologia e Análise de Sementes do Centro de Ciências Agrárias da UFES, foram avaliadas coloração do fruto; umidade, massa fresca, massa seca e germinação das sementes. O delineamento experimental utilizado foi o inteiramente casualizado, com quatro repetições de 25 sementes. A maturação fisiológica das sementes de Miconia cinnamomifolia ocorre entre 110 e 120 dias após a antese. Maior valor de perda de água da semente coincide com maior acúmulo de massa seca, que aumenta até cerca de 80 dias após a antese. A coleta das sementes na região serrana do Caparaó, deve ser feita próximo aos 110 dias da antese, quando a coloração dos frutos é preta e o teor de água das sementes é de aproximadamente $22,92 \%$. As sementes, sob condições naturais da região, germinam com 66 dias após a semeadura.
\end{abstract}

Termos para indexação: Miconia cinnamomifolia, maturação, germinação.

\begin{abstract}
Miconia cinnamomifolia it is na arboreal plant of the Melastomataceae family. This work aims to evaluate the physiological maturity and germination capacity of Miconia cinnamomifolia seed. The maturation study were conducted in the Serra do Caparaó, Ibitirama-ES, during 2000/2001 and 2001/2002. Each inflorescence was identified at anthesis. The treatments were constituted by six intervals of seed harvest, which were $35,50,65,80,95$ and 110 days after anthesis. The following parameters were evaluated: fruit color, seed moisture content, dry matter accumulation, germination test. The rehearsals were accomplished in Peter dish, in a fully randomized design with four replicates of 25 seeds. The results showed that the physiological maturity in miconia seeds occurs between 100 a 120 days after anthesis. Higher value of loss of water of the seed coincides with higher accumulation of dry mass, that increases until about 80 days after anthesis. The collection of the seeds in the serrana region of the Caparaó, must be made next to the 110 days to anthesis, when the coloration of the fruits is black and the seed water level is approximately $22,92 \%$. The seeds, under natural conditions of the region, germinated after 66 days the sowing.
\end{abstract}

Index terms: Miconia cinnamomifolia, maturity, germination.

(Recebido para publicação em 8 de setembro de 2005 e aprovado em 6 de março de 2006)

\section{INTRODUÇÃO}

A Miconia cinnamomifolia (DC.) Nand. também conhecida como micônia, carvalho vermelho, jacatirana ou guaratã é uma árvore perenifólia, espécie secundária inicial ou secundária tardia de intensa regeneração natural, que pode ser encontrada em associações mais evoluídas de vegetação secundária e como árvore rara nas clareiras da floresta primária, sendo característica da Floresta Ombrófila Densa (Floresta Atlântica). Espécie com características ornamentais devido à beleza de suas flores, tronco reto $\mathrm{e}$ levemente cônico, com ramificação cimosa, densa, e copa arredondada, apresentando flores pequenas, em panícula multifloral, perfumadas, que a caracterizam como planta de grande potencial para a arborização de parques e jardins. A maturação dos frutos é irregular e são avidamente procurados pela avifauna e a capacidade germinativa das sementes é baixa (CARVALHO, 1994; LORENZI, 1998).

A fase de máxima qualidade das sementes coincide com o ponto de maturação fisiológica, que compreende as transformações morfológicas, fisiológicas e funcionais que sucedem no óvulo fertilizado, que é atingida quando a semente apresenta máximo conteúdo de matéria seca e acentuada redução no teor de água, alterações visíveis no aspecto externo de frutos e sementes, culminando com

Professor do Departamento de Fitotecnia do Centro de Ciências Agrárias da Universidade Federal do Espírito Santo/CCA/UFES - Cx. P. 16 - $29500-000$ jclopes@cca.ufes.br

${ }^{2}$ Ms. Professora Voluntária do Departamento de Fitotecnia do Centro de Ciências Agrárias da Universidade Federal do Espírito Santo/CCA/UFES alinedsoares@hotmail.com 
máxima capacidade germinativa e vigor das mesmas (CARVALHO \& NAKAGAWA, 2000; POPINIGIS, 1985). Nesse ponto, a semente apresenta melhor nível de qualidade, devendo ser colhida.

O conhecimento do processo germinativo de sementes de espécies nativas, incluindo a época, é de relevante importância em pesquisas científicas, principalmente em trabalhos visando manejos de populações de plantas, que além de possibilitar maiores informações sobre as características das espécies permite auxiliar na busca de alternativas para o reflorestamento, arborização urbana e de rodovias, recomposição de áreas degradadas, na escolha de espécies que se adaptem às condições adversas de altas variações climáticas e edáficas no trópico úmido (BARBOSA et al., 1985; GONZÁLEZ, 1991; LORENZI, 1998; VAZQUEZ-YANES \& OROZCOSEGOVIA, 1984).

A germinação das sementes é variável de acordo com a temperatura, não havendo uma temperatura ótima e uniforme de germinação para todas as espécies. Em geral, a temperatura é fator determinante para a obtenção da germinação e está diretamente associada às características ecológicas da espécie (AGUIAR et al., 1993; POPINIGIS, 1985).

Em trabalhos de recomposição de paisagens degradadas por atividades extrativistas e outras exercidas pelo homem, torna-se necessário à obtenção de mudas de qualidade. A necessidade da realização de estudos que visem a ampliação dos conhecimentos do comportamento ecofisiológico das espécies nativas em diferentes ecossistemas, do ponto de maturação, da superação da dormência, uniformização e maximização da germinação das sementes de espécies para estes fins é, portanto, de grande importância. Considerando a ocorrência da espécie Miconia cinnamomifolia na região serrana do Parque do Caparaó, a uma altitude de 1100 metros, em formação pioneira, apresentando grande variação na época de floração, quando na obtenção das sementes e as dificuldades em obtê-las na região. Desta forma, com o presente trabalho, buscou-se estudar a maturação fisiológica das sementes de Miconia cinnamomifolia, visando determinar a época adequada de colheita.

\section{MATERIAL E MÉTODOS}

O trabalho foi conduzido na Fazenda Tecnotruta, reserva de Mata Atlântica existente no Pico da Bandeira, Serra do Caparaó, no Município de Ibitirama-ES e no Laboratório de Tecnologia e Análise de Sementes do
Departamento de Fitotecnia do Centro de Ciências Agrárias da Universidade Federal do Espírito Santo, Alegre-ES, utilizando-se sementes de Miconia cinnamomifolia (DC.) Naud, oriundas de matrizes localizadas na região.

Os estudos sobre maturação foram conduzidos na Serra do Caparaó, município de Ibitirama-ES, em dois períodos (2000/2001 e 2001/2002, devido às dificuldades de manutenção das sementes nas plantas, distância física e acesso ao local de ocorrência das plantas em estudo). No primeiro experimento, cada inflorescência foi etiquetada no dia 11 de novembro, data da antese, e acompanhado o enchimento de frutos e desenvolvimento das sementes até que atingissem o ponto de maturação. Nessa fase foram coletados frutos após atingirem a coloração preta e analisados em laboratório, sob condições ideais prédeterminadas em testes para a espécie, a coloração, o período de queda dos frutos, o teor de água das sementes, germinação e vigor.

No segundo experimento, a cada 15 dias e após a queda dos frutos, eles foram coletados manualmente $\mathrm{e}$ analisados quanto à coloração e teor de água; as sementes foram extraídas manualmente e avaliadas a capacidade germinativa; tempo gasto para germinar, sendo feitas às avaliações de germinação e tempo gasto para germinar em sementeiras montadas na região de estudo, contendo como substrato areia lavada. Em paralelo a essa avaliação, no laboratório foram conduzidos testes em câmara de germinação, sob controle de água, temperatura e luz.

$\mathrm{Na}$ análise de germinação, as sementes foram colocadas para germinar em placas de Petri previamente esterilizadas, forradas com papel de filtro, umedecido com água destilada e as placas mantidas nas câmaras de germinação à temperatura de $30^{\circ} \mathrm{C}$. A germinação foi avaliada através da porcentagem de plântulas normais e o vigor, através da velocidade de germinação (MAGUIRE, 1962). Em sementeiras, foram semeadas quatro repetições de 50 sementes, utilizando-se como substrato areia lavada e a germinação acompanhada pela emergência das plântulas no leito.

O delineamento utilizado foi o inteiramente casualizado, com quatro repetições de 50 sementes. As porcentagens de germinação foram transformadas para arc sen $\sqrt{X / 100}$, para fins de análise estatística e os dados para interpretação foram apresentados com as médias dos dados originais. Foram ajustadas equações de regressão de até terceiro grau para as principais características avaliadas e realizados estudos de correlação simples (r) entre os parâmetros. 


\section{RESULTADOS E DISCUSSÃO}

A antese da micônia, na região em estudo, ocorreu em épocas diferentes nos dois anos de avaliação. Em 2000/2001 teve início no mês de novembro (dia 11) e estendeu-se até início de janeiro de 2001. Em 2001/2002 teve início em dezembro (dia 02) e estendeu-se até março de 2002. Os dados médios mensais de temperaturas máximas, mínimas, médias compensadas, precipitação pluvial e umidade relativa ocorridas no período de colheita das sementes encontram-se na Figura 1. No primeiro período de avaliação, verificou-se a mudança de coloração dos frutos de verde para verde-arroxeado com cerca de 80 dias, passando à coloração preta, que, após oito a doze dias, coincidia com a queda dos mesmos, totalizando 104 dias após a antese. Nesse período, a avaliação do grau de umidade das sementes revelou valores de $16 \pm 3 \%$ e a capacidade germinativa das sementes era em média de $62 \%$, com índice de velocidade de emergência de 0,92 , em laboratório, sob condições controladas de luz, temperatura e umidade. No campo, em sementeiras, não se conseguiu obter germinação superior a $5 \%$, devido à freqüência e intensidade de chuvas na região, no período de avaliação, além das perdas de material devido ao consumo pela avifauna.

No segundo experimento sobre maturação das sementes de micônia (Tabela 1) montado na região serrana, no período de 2001/2002, os resultados obtidos evidenciam que da antese à maturação dos frutos transcorreram-se cerca de 110 dias, quando os frutos tinham coloração preta e iniciavam a queda. $\mathrm{O}$ início da frutificação ocorreu após 20 dias da antese. Os frutos apresentavam formato globoso e coloração verde durante a fase inicial até cerca de $80 \pm 10$ dias, passando a uma coloração arroxeada após cerca de 95 dias. Kanashiro \& Viana (1982) trabalhando com maturação de sementes de Cordia goeldiana Huber concluíram que a mudança de coloração do fruto era um bom indicador do ponto de maturação das sementes. Similaridade de resultados foi observada por Nakagawa et al. (1999) em sementes de azevém. Entretanto, Piña-Rodrigues et al. (1982), trabalhando com Dalbergia nigra Allem. ex Benth., sugeriram que a mudança na coloração dos frutos não fosse recomendada como índice de maturação. Após esse período, entre 110 a 125 dias, o formato dos frutos era esférico, com coloração preta e desprendiam-se da planta-mãe.

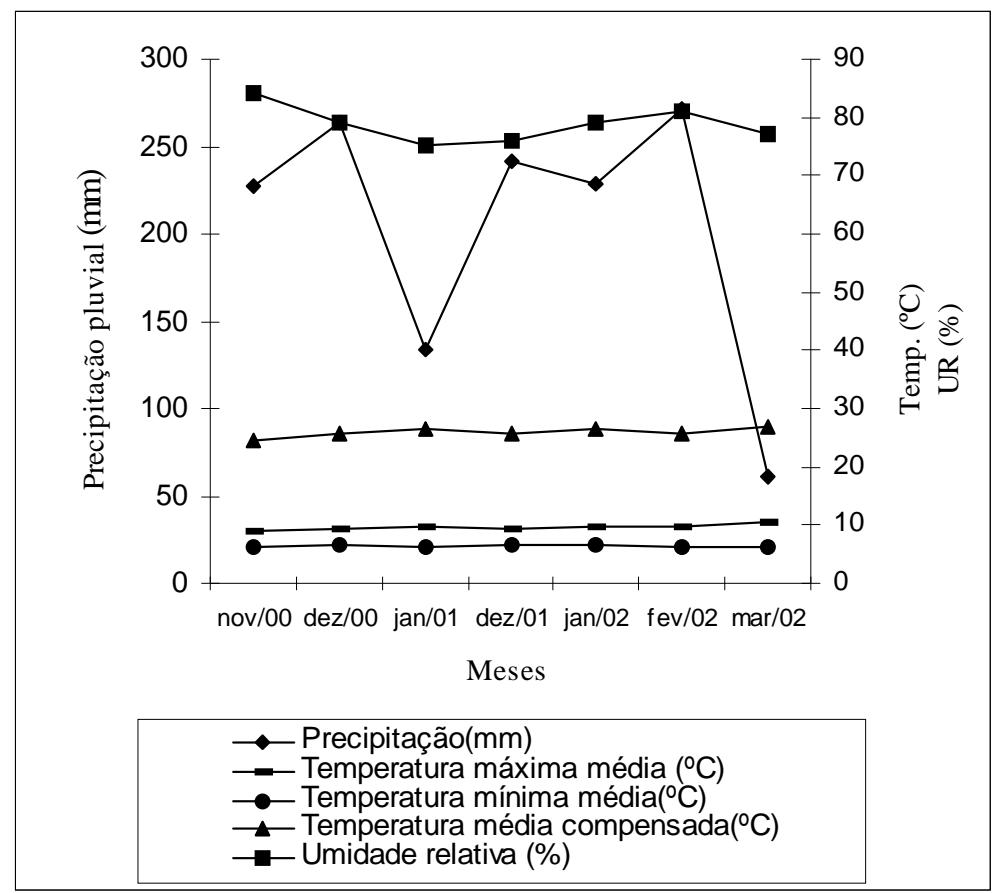

FIGURA 1 - Dados médios mensais de temperaturas máximas, mínimas, médias compensadas, precipitação pluvial, umidade relativa e período de colheitas das sementes de Miconia cinnamomifolia. Estação Agroclimatológica de Alegre-ES, Centro de Ciências Agrárias da UFES, Latitude: $20^{\circ} \mathrm{S}$; longitude: $41^{\circ} \mathrm{W}$; altitude: $150 \mathrm{~m}$. 
TABELA 1 - Dados relativos ao estudo da maturação das sementes de Miconia cinnamomifolia, na Região da Serra do Caparaó, em Ibitirama-ES. Laboratório de sementes, CCA-UFES. Alegre-ES, 2005.

\begin{tabular}{ccccccc}
\hline $\begin{array}{c}\text { Dias após } \\
\text { antese }\end{array}$ & $\begin{array}{c}\text { Poloração do } \\
\text { fruto }\end{array}$ & $\begin{array}{c}\text { Umidade } \\
\mathbf{( \% )}\end{array}$ & $\begin{array}{c}\text { Massa } \\
\text { Fresca } \\
(\mathbf{g} / \mathbf{5 0 0})\end{array}$ & $\begin{array}{c}\text { Massa Seca } \\
(\mathbf{g} / \mathbf{5 0 0})\end{array}$ & $\begin{array}{c}\text { Germinação } \\
(\boldsymbol{\%})\end{array}$ & $\begin{array}{c}\text { Tempo } \\
(\mathbf{d i a s})\end{array}$ \\
\hline 20 & Verde & 82,80 & 0,078 & 0,003 & 00 & 00 \\
35 & Verde & 61,38 & 0,101 & 0,039 & 00 & 00 \\
50 & Verde & 53,22 & 0,142 & 0,066 & 00 & 00 \\
65 & Verde & 35,15 & 0,202 & 0,131 & 5 & 90 \\
80 & verde-arroxeado & 25,20 & 0,242 & 0,181 & 16 & 71 \\
95 & verde-arroxeado & 23,79 & 0,248 & 0,189 & 22 & 71 \\
110 & Preto & 22,92 & 0,253 & 0,195 & 62 & 67 \\
125 & Preto & 17,94 & 0,234 & 0,192 & 56 & 67 \\
\hline
\end{tabular}

Os valores dos pesos de massa seca das sementes (Tabela 1) foram crescentes até 80 dias, tendo sido verificado maior acúmulo de massa seca após 65 e 80 dias da antese. Após esse período, verificou-se um pequeno aumento até cerca de 110 dias.

No teste de germinação, feito com as sementes colhidas após 35 e 50 dias, não se verificou germinação (Tabela 1 e Figura 2). Após 65 dias obteve-se apenas $5 \%$ de germinação e o tempo gasto para que as sementes germinassem foi de 90 dias. Martins \& Silva (1997), trabalhando com Dalbergia nigra, também não obtiveram germinação na fase inicial durante as três primeiras colheitas de sementes.

Embora a porcentagem de germinação tenha sido baixa em relação aos períodos posteriores, verificou-se uma coincidência entre maiores valores de perda de água da semente nessa fase $(18,37 \%)$ com maior aumento do conteúdo de massa seca nas mesmas $(0,131 \mathrm{~g} / 500$ sementes), cujo aumento foi de $49,62 \%$. Verifica-se pela correlação entre as características analisadas que houve uma correlação negativa entre o teor de água $(r=-0,96)$ e $o$ conteúdo de massa seca de 500 sementes. A coloração dos frutos nessa fase ainda era verde. Esses dados corroboram a afirmação de Carvalho \& Nakagawa (2000), que o ponto em que as sementes atingem o máximo de conteúdo de massa seca pode coincidir com a maior redução no conteúdo de água.

Entretanto, Guimarães et al. (1998), trabalhando com Zinnia elegans Jacq., constataram que este parâmetro não pode ser utilizado de maneira eficaz como índice de maturidade, corroborando os resultados obtidos por Leonhardt et al. (2001), em sementes de tumarã-de-espinho. Maiores valores de massa seca das sementes coincidiram com maior capacidade germinativa, após 80 dias da antese, mantendo-se praticamente constantes após esse período.
Houve redução progressiva e paulatina, do teor de água das sementes sendo mais acentuada entre 35 e 65 dias, quando a coloração dos frutos era totalmente verde, passando de $61,38 \%$ para $35,15 \%$ (Figura 2). Após 80 dias, o teor de água registrou valores de $25,20 \%$, atingindo 22,92\% após 110 dias, quando se verificou uma diminuição mais lenta no conteúdo de água. Entre 110 e 125 dias foram feitas análises somente das sementes dos frutos coletados no chão, obtendo-se um teor de água de $17 \%$.

Após 80 e 95 dias obteve-se porcentagens de sementes germinadas de 16 e $22 \%$, respectivamente, tendo atingido $62 \%$ após 110 dias da antese e 56\% após 125 dias. Nesse período, verificou-se ocorrência de queda de frutos acentuada nas plantas. Em sementeiras, foi alcançada porcentagem de germinação de $56 \%$ após 66 dias da semeadura, nas condições de ambiente natural. Verifica-se que houve redução no tempo médio gasto para as sementes germinarem, e aumento na porcentagem de germinação, à medida que o grau de maturação foi aumentando, que de acordo com Silva \& Nakagawa (1995), esse tempo médio que as sementes levam para germinar é também um índice associado ao vigor. Esse resultado observado contrasta as informações de Lorenzi (1998), que embora também tenha verificado que a germinação dessa espécie é baixa e moderada, a germinação feita sob condições de campo levou tempo superior ao previsto pelo autor, concordando com os resultados de Carvalho (1994). As diferenças de germinação e de período de maturação verificadas podem possivelmente ser explicadas pelas oscilações de temperaturas ocorridas na região durante a condução dos experimentos, conforme pode ser verificado na Figura 1. As sementes extraídas de frutos colhidos no chão, imediatamente após a queda, apresentaram germinação média, em laboratório, de cerca de $62 \%$.

Ciênc. agrotec., Lavras, v. 30, n. 4, p. 623-628, jul./ago., 2006 

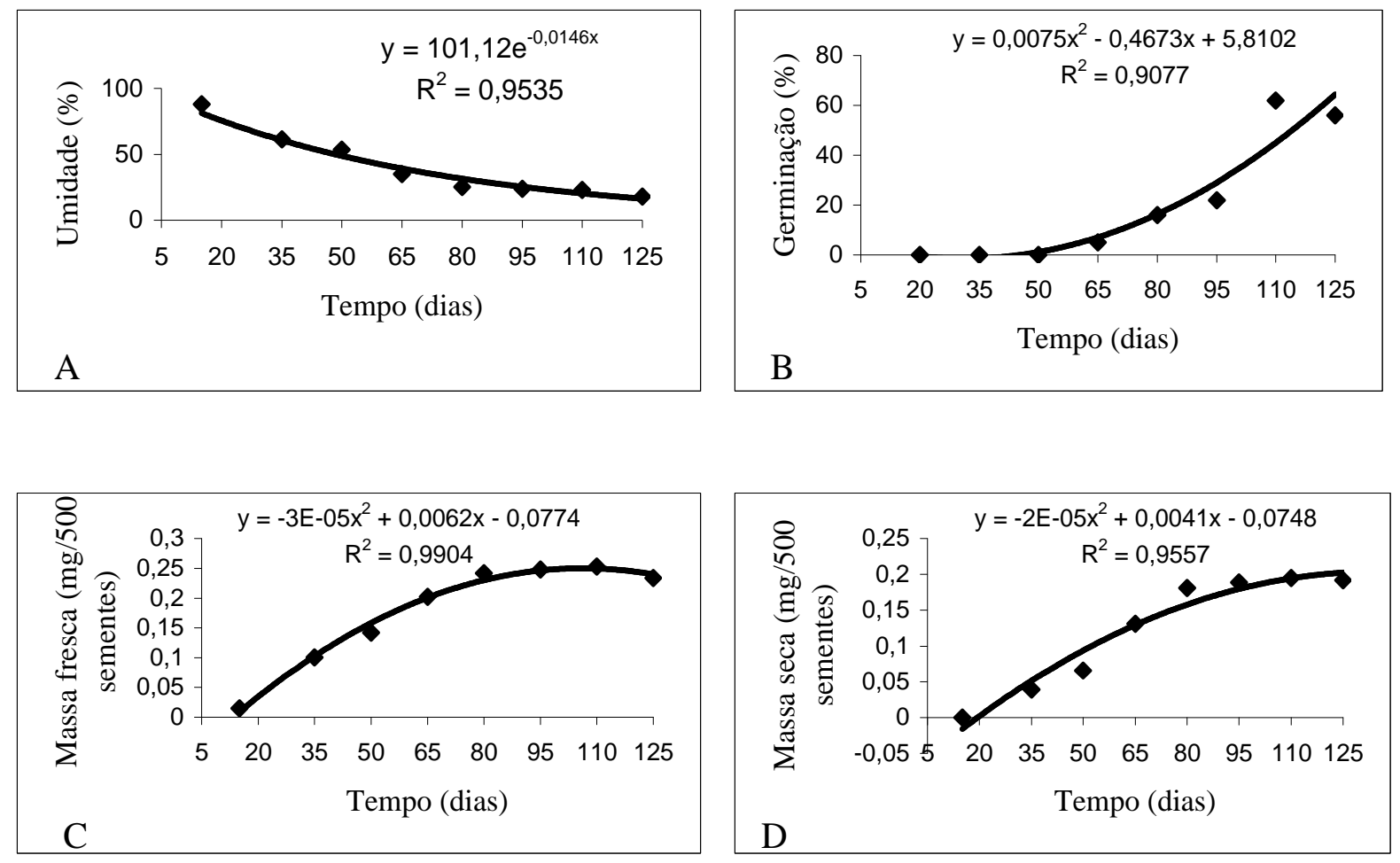

FIGURA 2 - Umidade (A), Germinação (B), Massa fresca (C) e Massa seca (C) de sementes de Miconia cinnamomifolia. Laboratório de sementes, CCA - UFES, Alegre-ES, 2005.

\section{CONCLUSÕES}

a) Maior valor de perda de água da semente de Miconia cinnamomifolia coincide com maior acúmulo de massa seca nas mesmas;

b) A época de coleta das sementes de Miconia cinnamomifolia, na região serrana do Caparaó, deve ser feita próximo aos 110 dias da antese, com teor de água de $22,92 \%$;

c) Na maturação, a coloração dos frutos é preta, coincidindo com a deiscência entre 110 a 125 dias da antese;

d) A massa seca das sementes de Miconia cinnamomifolia aumenta durante a fase de maturação até aproximadamente 80 dias após a antese;

e) Sob condições naturais, em regiões de clima similar ao de desenvolvimento deste trabalho, as sementes maduras germinam com 66 dias após a semeadura;

\section{AGRADECIMENTOS}

Ao CNPq pela concessão de bolsa de iniciação científica ao segundo autor; à Eng ${ }^{\mathrm{a}} \mathrm{Agr}^{\mathrm{a}}$ Marilda Torres
Capucho, aos proprietários da Fazenda Tecnotruta em Ibitirama-ES, pelo apoio e auxílios prestados na preservação, acesso e coleta de sementes na região do Parque Nacional do Caparaó.

\section{REFERÊNCIAS BIBLIOGRÁFICAS}

AGUIAR, I. B.; PIÑA-RODRIGUES, F. C. M.; FIGLIOLIA, M. B. Sementes florestais tropicais. Brasília, DF: ABRATES, 1993.350 p.

BARBOSA, J. M.; BARBOSA, L. M.; PINTO, M. M. Influência do substrato, da temperatura e do armazenamento sobre a germinação de quatro espécies nativas. Ecossistema, Espírito Santo do Pinhal, v. 10, n. 1, p. 46-54, 1985.

CARVALHO, N. M.; NAKAGAWA, J. Sementes: ciência, tecnologia e produção. 4. ed. Jaboticabal: FUNEP, 2000. $588 \mathrm{p}$. 
CARVALHO, P. E. R. Espécies florestais brasileiras: recomendações silviculturais, potencialidades e uso da madeira. Colombo: Embrapa/CNPF, 1994. 640 p.

GONZÁLEZ, E. J. Recolección y germinacion de semillas de 26 especies arbóreas del bosque húmedo tropical. Revista de Biologia Tropical, [S.1.], v. 39, n. 1, p. 47-51, 1991.

GUIMARÃES, T. G.; OLIVEIRA, D. A.; MANTOVANIALVARENGA, E.; GROSSI, L. A. S. Maturação fisiológica de sementes de zínia (Zinia elegans Jacq.). Revista Brasileira de Sementes, Brasília, v. 20, n. 1, p. 7-11, 1998.

KANASHIRO, M.; VIANA, N. G. Maturação de sementes de Cordia goeldinana Huber. Belém, PA: Embrapa/CPATU, 1982. 11 p. (Circular técnica, 28).

LEONHARDT, C.; TILLMANN, M. A. A.; VILLELA, F. A.; MATTEI, V. L. Maturação fisiológica de sementes de tarumã-de espinho (Citharexylum montevidense (Spreng.) Moldenke - Verbenaceae), no jardim botânico de Porto Alegre, RS. Revista Brasileira de Sementes, Brasília, v. 23, n. 1, p. 100-107, 2001.

LORENZI, H. Árvores brasileiras: manual de identificação e cultivo de plantas arbóreas nativas do Brasil. Nova Odessa: Plantarum, 1998. v. 1, 352 p.

MARTINS, S. V.; SILVA, D. D. Maturação e época de colheita de sementes de Dalbergia nigra (Vell.) Fr.All.ex Benth. Revista Brasileira de Sementes, Brasília, v. 19, n. 1, p. 96-99, 1997.
MAGUIRE, J. B. Speed of germination-aid in selection and evaluation for seedling emergence vigor. Crop Science, Madison, v. 2, n. 2, p. 176-177, 1962.

MAYER, A. M.; POLJAKOFF-MAYBER, A. The germination of seeds. 4. ed. Oxford: Pergamon, 1989. 270 p.

NAKAGAWA, J.; CAVARIAN, C.; FELTRAN, J. C.; OLIVEIRA, R. L. Maturação de sementes de azevém (Lolium multiflorum Lam.). Revista Brasileira de Sementes, Brasília, v. 21, n. 1, p. 174-182, 1999.

PIÑA-RODRIGUES, F. C. M.; JESUS, R. M.; MENANDRO, M. Maturação de sementes de Dalbergia nigra Fr.Allen. utilização da coloração dos frutos como índice de maturação. In: CONGRESSO FLORESTAL ESTADUAL, 5., 1984, Nova Prata, RS. Anais... Nova Prata: Governo do Estado do Rio Grande do Sul, 1984. v. 2, p. 17-22.

POPINIGIS, F. Fisiologia da semente. Brasília, DF: AGIPLAN, 1985. 289 p.

SILVA, J. B. C.; NAKAGAWA, J. Estudos de fórmulas para cálculo da velocidade de germinação. Informativo ABRATES, Londrina, v. 5, n. 1, p. 62-73, 1995.

VAZQUEZ-YANES, C.; OROZCO-SEGOVIA, A. Ecophysiology of seed germination in the tropical humid forest of the world: a review. In: MEDINA, E.; MONEY, H. A.; VAZQUEZ-YANES, C. (Eds.). Physiological ecology of plants of the wet tropics. The Hague: W. Junk, 1984. p. 37-50. 